\title{
Effect of one minute preceptor (OMP) model in learning of core competencies in Pharmacology
}

\author{
Shalini Chandra', Marya Ahsan ${ }^{2}$, Sameer Chandra ${ }^{3}$, Iram Shaifali ${ }^{4, *}$, Rakesh Koul ${ }^{5}$ \\ ${ }^{\mathbf{1}}$ Professor \& Head, ${ }^{\mathbf{2}, 3}$ Associate Professsor, ${ }^{\mathbf{4}, \mathbf{5}}$ Assistant Professor, ${ }^{\mathbf{1}, \mathbf{2 , 4}, \mathbf{5}}$ Dept. of Pharmacology, 3Dept. of Surgery, Rohilkhand \\ Medical College \& Hospital, Bareilly, Uttar Pradesh, India
}

*Corresponding Author:

Email: pharmarohilkhand@gmail.com

\begin{abstract}
Introduction: Knowledge and competencies regarding Pharmacology are found difficult to be taught by the traditional teaching methodologies alone. One minute preceptor (OMP) model is an innovative method of teaching and learning activity which is being used to improve reasoning skills in clinical settings but also can be used with modification to improve work place based learning in nonclinical subjects. We conducted OMP for the first time among undergraduate students with the aim of imparting better understanding of basic competencies in Pharmacology and better clinical application of concepts.

Materials and Methods: This was a quasi experimental interventional study. Participants included 60 undergraduate second BBS students that were randomized to the OMP group $(n=30)$ or to the traditional group $(n=30)$ and 12 faculty members. Six competencies of Pharmacology were selected and validated by the content experts followed by development and validation of six case scenarios from the topics chemotherapy and cardiovascular system (CVS) with regards to the particular competency. One case scenario was developed for one competency. The selected topics had already been covered in didactic lecture. Validated pre/post-test questionnaire and feedback perception questionnaire were developed. Faculty and students were sensitized with the OMP method of teaching with short interactive lecture and role play. Immediate cognitive gain was assessed using pre- and posttests for each intervention. Formative assessment after 2 months was done to assess long term impact using structured viva. All the questions were based on clinical application with regards to the competencies. Students' and faculty perceptions were analyzed using feedback questionnaire on a 5-point Likert's scale. Paired t- test was adopted to assess pre/post scores for immediate effect of learning. Unpaired t-test was conducted to compare viva scores between two groups to assess long term impact.

Results: Analysis of results of the both group revealed that OMP group scoring was significantly higher than the traditional group .The average perception on Likert's scale was between 4(agree) and 5(strongly agree). The OMP model of teaching learning in pharmacology was well perceived by the students and faculty. Teaching skills of the faculty were also improved.

Conclusion: Faculties and students rate OMP as more effective model of teaching than traditional model. Students feel confident in applying concepts in clinical settings. OMP promotes self directed learning and encompasses all three domains- cognitive, psychomotor and affective.
\end{abstract}

Keyword: OMP, Undergraduates, Competencies, Pharmacology.

\section{Introduction}

Pharmacology is often considered a difficult learning subject for the undergraduates. Teaching Pharmacology requires multiple approaches. Knowledge and competencies regarding Pharmacology are found difficult to be taught by the traditional teaching methodologies alone and is not found to prepare students to understand the concepts of subject, its rational therapeutics. Efficient work place based learning is lacking with traditional approaches. Currently didactic lectures, tutorials and seminars are the common teaching activities held in Pharmacology to undergraduates in second professionals in our institute. Teachers usually provide little or no feedback and there is passive transfer of lecture content to students instead of promoting discussion. The reason might be because of unstructured way of teaching which could have led to student dissatisfaction and decreased learning. Undergraduates are not prepared enough to apply concepts of Pharmacology in clinical postings. This has brought a major challenge in teaching students to choose and prescribe medicines safely and effectively in our institute.

In medical education literature many approaches have been described to improve work place based learning. Few are One minute preceptor (OMP); SNAPPS (Summarize, Narrow, Analyze, Probe, Plan and Self-directed learning); Aunt Minnie and Activated Demonstration. Amongst all OMP have been studied extensively in clinical specialties to teach short cases. ${ }^{1}$ Further Weitzel KW et al reported that a variety of validated teaching methods can be used to adapt to individual learner needs while meeting overall program goals and objectives. ${ }^{2}$ The One-Minute Preceptor (OMP) is a learner-centred, validated and innovative method of teaching and learning tool to improve reasoning skills in clinical settings. ${ }^{3}$ This approach was first published over 25 years ago and was described in the beginning for use by faculty in busy ambulatory settings. ${ }^{4,5}$ However this model can be used to teach reasoning skills in non clinical areas as well. ${ }^{6}$ It allows learner and teacher to identify knowledge gaps and focus learning which involves standard process with 
checklists and criticism. ${ }^{7}$ The core strength of the study is in the systematic approach in the form of 5 microskills (See Table 1). Each skill is an individual teaching methodology, when combined forms an effective way of structured teaching including immediate, direct feedback. They are called as micro skills because they are very simple and easy to learn.
Out of these 5 micro skills, the first two diagnose learners knowledge and reasoning and the last three offer tailored instructions. ${ }^{4,6}$ There are many ways the OMP may be adopted and adapted to your teaching style and the circumstances in which you teach and It can be used in situation concerning critical thinking in which quick feedback is required. ${ }^{8,9}$

Table 1: 5 micro skills covered in OMP

\begin{tabular}{|c|l|l|}
\hline & \multicolumn{1}{|c|}{ Micro skills } & \\
\hline 1 & Get a commitment & What do you think is going on? \\
\hline 2 & $\begin{array}{l}\text { Probe for supporting } \\
\text { evidence }\end{array}$ & Why do you think this? \\
\hline 3 & Teach general rules & $\begin{array}{l}\text { Teach the learner common "take-home points" } \\
\text { that can be used in future cases, aimed } \\
\text { preferably at an area of weakness for the learner }\end{array}$ \\
\hline 4 & $\begin{array}{l}\text { Reinforce what was } \\
\text { done well }\end{array}$ & $\begin{array}{l}\text { Tell them what they did right and the effect that } \\
\text { it had. }\end{array}$ \\
\hline 5 & $\begin{array}{l}\text { Correct errors/provide } \\
\text { feedback }\end{array}$ & $\begin{array}{l}\text { Provide constructive feedback with } \\
\text { recommendations for improvement. }\end{array}$ \\
\hline
\end{tabular}

No studies have been conducted to assess the effectiveness of this model to enhance learning and reasoning in the subject Pharmacology especially among undergraduates. Hence, we proposed that this OMP model could be used as an effective teaching learning tool with the aim of imparting better understanding of basic competencies in Pharmacology and better clinical application

The objectives of the study were:

1. To sensitize faculties of Pharmacology about OMP model

2. To implement OMP model for teaching selected competencies in Pharmacology

3. To measure the impact of OMP model on 2nd professional undergraduate medical students

4. To assess the perception of teachers and students regarding OMP model.

\section{Materials and Methods}

Sample size: 60 undergraduate students, 12 faculty members including tutors

Study design: Quasi experimental study design

Randomization: simple randomization by random sequence generator
The study was approved by institutional ethical committee.

The Methodology is divided into 4 phases:

Phase 1: Selection of competencies and development of case scenarios

Phase 2: Validation of pretest and post-test questions and feedback questionnaires

Phase 3: Sensitization of faculties and students about OMP model

Phase 4: Baseline evaluation, comparison and evaluation between groups

\section{Phase 1: Selection of competencies and development of case scenarios:}

1. Focus group discussions (FGD) were held with faculty members to select and finalize the competencies and case based scenarios.

2. Six competencies followed by development and validation of six case scenarios which were of the must know category, were finalized by content experts for testing between OMP and traditional groups in the FGD session from the topics chemotherapy and cardiovascular system (CVS). Each case scenario was developed with regards to the particular competency (Table 2).These topics had already been covered in didactic lectures.

Table 2: Six competencies and respective case scenarios

\begin{tabular}{|l|l|}
\hline \multicolumn{1}{|c|}{ Competencies } & \multicolumn{1}{c|}{ Case scenarios } \\
\hline $\begin{array}{l}\text { Plan rationale } \\
\text { therapy for } \\
\text { common clinical } \\
\text { conditions }\end{array}$ & $\begin{array}{l}\text { A farmer with a history of handling insecticide was brought } \\
\text { to the hospital with convulsions, sweating, laboured } \\
\text { breathing. On examination his pupils were constricted, pulse } \\
\text { was 50/min. RR was high and on auscultation rales and } \\
\text { ronchi heard all over the lungs. What is the diagnosis? } \\
\text { Outline the management? }\end{array}$ \\
\hline Calculate & A 60 kg man, aged 32 years, truck driver by occupation \\
\hline
\end{tabular}




\begin{tabular}{|l|l|}
\hline appropriate doses & $\begin{array}{l}\text { presented medicine OPD with complaints of fever, chronic } \\
\text { cough with sputum which is yellowish in colour, since last } \\
\text { 25 days. On examination sputum was AFB positive and } \\
\text { chest X ray showed cavitatory lesions in right middle lobe. } \\
\text { The patient as diagnosed a case of category 1 tuberculosis. } \\
\text { Calculate the doses of individual drugs to be given. }\end{array}$ \\
\hline $\begin{array}{l}\text { Appropriate } \\
\text { information } \\
\text { about medicines }\end{array}$ & $\begin{array}{l}\text { A patient name Ramesh aged around 60yrs, resident of } \\
\text { Delhi, comes to medicine emergency with chief c/o chest } \\
\text { tightness and discomfort and dyspnea during brisk walking } \\
\text { or climbing stairs. He also c/o sub-sternal pain radiates to } \\
\text { left arm, neck and jaw on exertion. On examination his vital } \\
\text { signs are within normal range. Write the diagnosis and } \\
\text { management. What information would you like to give to } \\
\text { the patient regarding administration of drug? }\end{array}$ \\
\hline $\begin{array}{l}\text { Detect adverse } \\
\text { drug reactions }\end{array}$ & $\begin{array}{l}\text { A 29 years old man was prescribed an antibiotic for some } \\
\text { sore throat infection. Within 3 mins after taking the } \\
\text { injection he developed generalized pruritus, flushing, } \\
\text { followed by nausea and vomiting and fainted. Later he } \\
\text { developed cyanosis with a pulse of 120 / min and BP 80/50 } \\
\text { mm of Hg. After 12 hours on questioning said that he had } \\
\text { taken the same drug on previous occasion. What is the likely } \\
\text { diagnosis? What could be the antibiotic that produced this } \\
\text { condition? Drug of choice to treat patient's worsening } \\
\text { symptoms? }\end{array}$ \\
\hline $\begin{array}{l}\text { Mahesh a poor rickshaw driver, 45 year-old male patient } \\
\text { visited OPD with complains of bloody, mucoid stools and } \\
\text { abdominal pain. There is no history of alcohol abuse. It was } \\
\text { diagnosed it as a case of acute amoebic dysentery. Choose } \\
\text { an effective group according to criteria. Choose a P-drug } \\
\text { and mention its dosage schedule and duration of treatment. }\end{array}$ \\
\hline $\begin{array}{l}\text { A patient aged 70 years and suffering from chronic CHF is } \\
\text { receiving Digoxin for the past few months. He is also } \\
\text { receiving Furosemide as adjuvant treatment. Gradually he } \\
\text { develops bradycardia, ventricular ectopics, muscle weakness } \\
\text { and cramps in the leg. What could be the reason for } \\
\text { interaction }\end{array}$
\end{tabular}

Phase 2: Validation of pretest and post-test questions and feedback questionnaires: Perception of OMP was evaluated by validated feedback forms based on standard 5 points likert's scale. These questionnaire were based on already conducted surveys. ${ }^{1,4}$ Few questions have been modified and questionnaire was again validated and tested for reliability in our settings (cronbach's alpha $=0.853$ and 0.769 for faculty and student perception questionnaire respectively.

Phase 3: Sensitization of faculties and students about OMP model: One day training of faculties and students regarding OMP by short interactive lecture and role play was conducted for proper facilitation of OMP and proper understanding of 5 micro skills. In addition faculties were also sensitized for giving feedback.

Phase 4: Baseline evaluation, comparison and evaluation between groups: Pretest was conducted before sensitization program to assess baseline information about the faculties about OMP which was followed by post-test (to assess impact of training).
The two groups of students were evaluated ( as multiple choice questions) for baseline comparability regarding knowledge of topics chemotherapy and cardiovascular system already taught in didactic lectures Pre-test and post-test ( as multiple choice questions) were conducted before and after the sessions in both OMP and traditional groups to see immediate cognitive gain. To assess long term impact formative assessment was done in the form of structured viva 2 months after completion of the topics. All the questions were based on clinical application with regards to the competencies

Overall process: The students were randomized to one of two groups as group A and group B. Group A was taught by OMP and group B by traditional method on the case scenarios to mimic the clinical settings. The project is carried out once a week during tutorial session in Pharmacology.

OMP group: 30 students were divided into 2 batches, each comprising 15 participants. In each batch, every 
learner was encountered individually (one learner with one preceptor). Other students were observing the teaching sessions. Time allotted for each session was 60 minutes. Average time spent on each encounter was approximately 7 minutes. So total time for each session was approximately 105 minutes which exceeded the duration of allotted time. So the session could not be finished with in the allotted time and extra time was devoted.

Traditional group: 30 students were divided into 2 batches, each comprising 15 participants. One faculty taught all the students in each batch.Time allotted for each session was 60 minutes.

There were six such sessions for both OMP and traditional group, each of one competency.

\section{Data Analysis}

Student $t$ test was adopted to assess pretest and post test scores. Perception of faculties and students about OMP model of teaching was evaluated by feedback questionnaire on standard 5 point's Likert's scale (1=strongly

agree,

2=agree, $3=$ neutral,4=disagree, $5=$ strongly disagree) .

Data was analyzed using SPSS software version 21 and Microsoft excel version 2007. p value less than 0.05 was taken significant for all the evaluations.

\section{Results}

The total number of participants was 12 faculty members including 4 tutors and 60 second professional undergraduate students who gave informed consent for participation. The baseline knowledge between OMP and traditional groups were found to be comparable ( $\mathrm{p}$ value $=0.89$ ). The faculty response rate was $100 \%$ for both pretest as well as post-test questionnaires. Pre-test and post-test responses were analyzed to assess impact of training (Table 3). 10 pre validated short answer questions (SAQs) were administered in both pre and post tests. There was a statistically significant difference in all the 10 attributes. This reflected significant learning.

Table 3: Impact of training of the faculty (after sessions on OMP)

\begin{tabular}{|c|c|c|c|}
\hline & Pretest/Post-test Questions & $\begin{array}{c}\text { Pre-test } \\
\text { responses }(\%) \\
(n=12)\end{array}$ & $\begin{array}{c}\text { Post-test } \\
\text { responses }(\%) \\
(n=12)\end{array}$ \\
\hline 1. & $\begin{array}{l}\text { Have you heard about one minute } \\
\text { preceptor model of teaching? }\end{array}$ & 50 & 100 \\
\hline 2. & $\begin{array}{l}\text { How many microskills are there in } \\
\text { OMP? }\end{array}$ & 17 & 100 \\
\hline 3. & $\begin{array}{l}\text { Do you know the average time } \\
\text { required to conduct the one session } \\
\text { of OMP? }\end{array}$ & 40 & 100 \\
\hline 4. & $\begin{array}{l}\text { Do you know the meaning of } \\
\text { preceptor? }\end{array}$ & 62 & 100 \\
\hline 5. & What does one minute indicate? & 30 & 100 \\
\hline 6. & $\begin{array}{l}\text { Does feedback is given in OMP to } \\
\text { students? }\end{array}$ & 24 & 100 \\
\hline 7. & $\begin{array}{l}\text { Can you note the order of steps } \\
\text { involved in the OMP? }\end{array}$ & 24 & 70 \\
\hline 8. & $\begin{array}{l}\text { Does OMP Improve thinking and } \\
\text { reasoning skills? }\end{array}$ & 24 & 70 \\
\hline 9. & $\begin{array}{l}\text { Does OMP a flexible and pliable } \\
\text { model or static and rigid model? }\end{array}$ & 24 & 90 \\
\hline 10. & $\begin{array}{l}\text { Is it different from traditional } \\
\text { teaching? }\end{array}$ & 30 & 74 \\
\hline
\end{tabular}

Table 4 shows comparison of two groups' results on different competencies after assessing pretest and posttest questions (as multiple choice questions). There is statistically significant improvement in post-test $s c o r e s(p<0.001)$ in both the groups for all the competencies. This revealed that both the teaching methods had significant effect on immediate cognitive gain. However, the OMP group showed higher gain in post-test scores $(\mathrm{p}<0.001)$ than traditional group in all the competencies reaching statistical significance as noted in table 5. Table 6 depicts long term impact (after 2 months as formative assessment) in the form of structured viva. OMP group showed greater retention of knowledge and secured significantly higher marks ( $p$ value $=0.02$ ) as compared to traditional group.

Table 4: Comparison of pretest and post test scores of group A(OMP) and Group B(Traditional) to assess immediate cognitive gain 


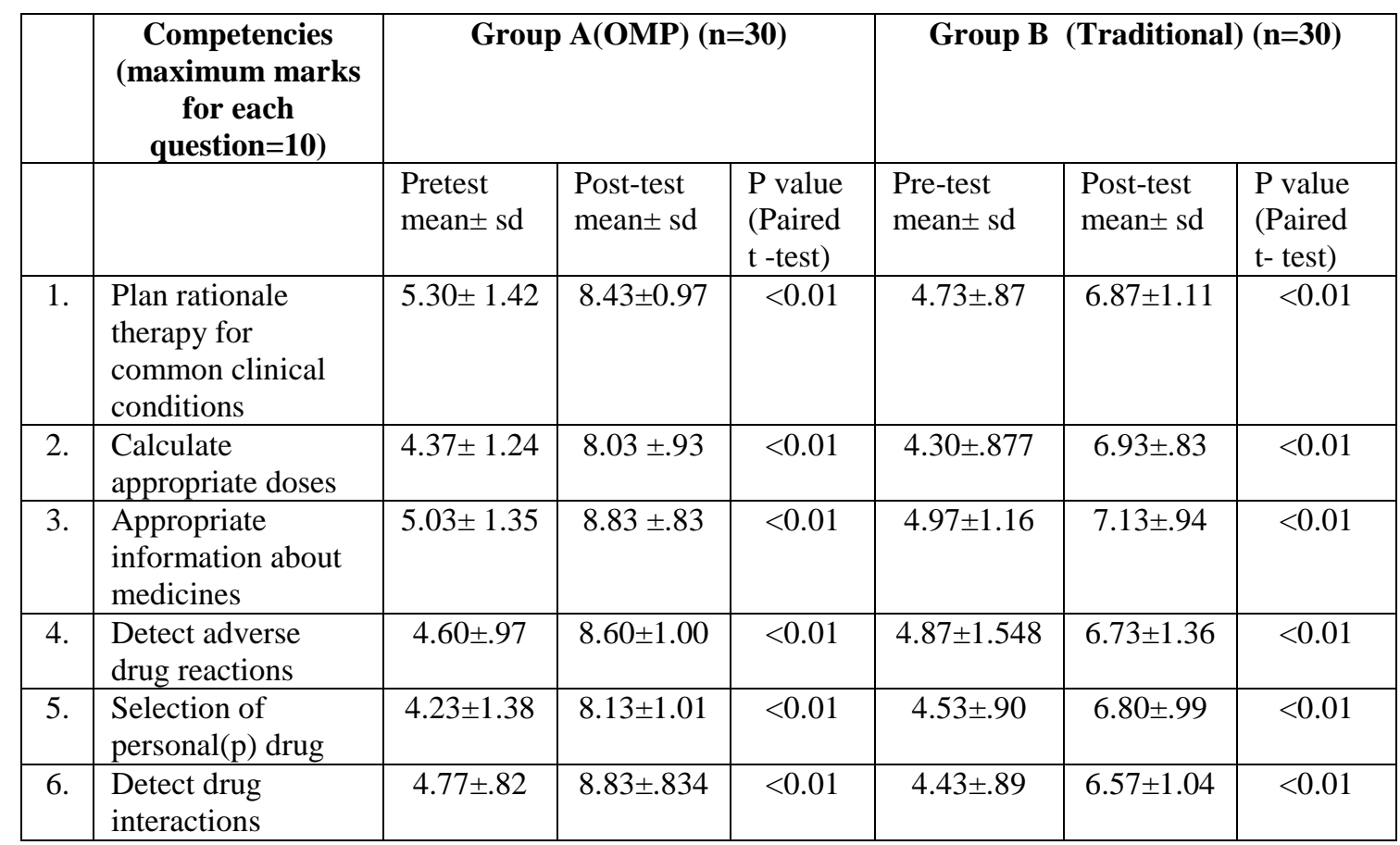

Table 5: Comparison of Post-test scores between OMP and traditional groups

\begin{tabular}{|c|c|c|c|c|}
\hline & $\begin{array}{l}\text { Competencies } \\
\text { (maximum marks for each } \\
\text { question=10) }\end{array}$ & $\begin{array}{l}\text { Post-test scores } \\
\text { OMP }(\mathbf{n}=30) \\
\text { (Group A) } \\
\text { mean } \pm \text { sd }\end{array}$ & $\begin{array}{l}\text { Post-test scores } \\
\text { traditional } \\
(\mathbf{n}=\mathbf{3 0} \\
(\text { Group B) } \\
\text { mean } \pm \text { sd }\end{array}$ & P value \\
\hline 1. & $\begin{array}{l}\text { Plan rationale therapy for common } \\
\text { clinical conditions }\end{array}$ & $8.43 \pm 0.97$ & $6.87 \pm 1.106$ & $<0.001$ \\
\hline 2. & Calculate appropriate doses & $8.03 \pm .93$ & $6.93 \pm .83$ & $<0.001$ \\
\hline 3. & $\begin{array}{l}\text { Appropriate information about } \\
\text { medicines }\end{array}$ & $8.83 \pm .83$ & $7.13 \pm .94$ & $<0.001$ \\
\hline 4. & Detect adverse drug reactions & $8.60 \pm 1.00$ & $6.73 \pm 1.36$ & $<0.001$ \\
\hline 5. & Selection of personal(p) drug & $8.13 \pm 1.01$ & $6.80 \pm .99$ & $<0.001$ \\
\hline 6. & Detect drug interactions & $8.83 \pm .83$ & $6.57 \pm 1.04$ & $<0.001$ \\
\hline
\end{tabular}

Table 6: Comparison of mean scores obtained in structured viva voce between two groups

\begin{tabular}{|l|c|c|c|}
\hline & $\begin{array}{c}\text { OMP } \\
\text { Mean } \pm \text { sd } \\
(\mathbf{n}=\mathbf{3 0})\end{array}$ & $\begin{array}{c}\text { Traditional } \\
\text { Mean } \pm \mathbf{s d} \\
(\mathbf{n}=\mathbf{3 0})\end{array}$ & $\begin{array}{c}\text { P value } \\
(\text { unpaired } \\
\text { t test })\end{array}$ \\
\hline $\begin{array}{l}\text { Viva marks } \\
\text { Maximum marks? } \\
\text { per question =2) }\end{array}$ & $1.08500 \pm .083$ & $0.97667 \pm 0.11$ & 0.024 \\
\hline
\end{tabular}

To assess the overall perception of faculties on OMP model thirteen questions were asked in the faculty perception questionnaire. The findings are summarized in Table 7. In 3 out of 13 parameters faculty strongly agreed that they had covered all the 5 microskills (5), they were able to bring out strengths and weakness of the students (5) ,however they also found OMP to be much time consuming $(5 \pm 0.00)$. Most of the faculty members agreed that OMP was helpful in motivating students (4.5), good to update faculty (4.5) and raised academic performance by the students (4.33 .492). However opinion varied from scale 3 to 4 regarding comfort with OMP. Most faculties agreed that OMP should be adopted as a teaching methodology (3.92) especially for must know areas in Pharmacology in addition to traditional. 
Table 7: Perception of faculty on 5 point likert's scale (Strongly agree=5, Agree=4, Neutral=3, Disagree=2, Strongly disagree $=1$ )

\begin{tabular}{|c|l|c|}
\hline \multicolumn{1}{|c|}{ Questions } & $\begin{array}{c}\text { Mean } \\
\text { perception } \\
(\mathbf{n = 1 2})\end{array}$ \\
\hline 1. & You were comfortable with this method of OMP. & 3.6 \\
\hline 2. & It is different than traditional method of teaching. & 4.4 \\
\hline 3. & $\begin{array}{l}\text { You have covered all the microskills including } \\
\text { feedback. }\end{array}$ & 5 \\
\hline 4. & $\begin{array}{l}\text { OMP creates healthy relationship between teacher \& } \\
\text { learner. }\end{array}$ & 4 \\
\hline 5. & You found students to be comfortable with OMP. & 3.83 \\
\hline 6. & OMP is time consuming. & 5 \\
\hline 7. & OMP motivates students for gaining wider knowledge. & 4.5 \\
\hline 8. & OMP is better than traditional teaching. & 4.3 \\
\hline 9. & OMP raises overall performance of students. & 4.3 \\
\hline 10. & OMP encompasses all three cognitive, psychomotor & 4.5 \\
\hline 11. & OMP brings out strengths and weaknesses of students. & 5 \\
\hline 12. & OMP improves reasoning skills of the students. & 4.5 \\
\hline 13. & $\begin{array}{l}\text { OMP should be a regular feature of undergraduate } \\
\text { teaching in Pharmacology. }\end{array}$ & 3.9 \\
\hline
\end{tabular}

The OMP group student's response to the questionnaire revealed high satisfaction with this teaching methodology (Table 8) .Students stated that they were comfortable with OMP (4). They felt that OMP helped in improving their reasoning ability (4.36) and this approach of teaching had stimulated them to further read the subject (4.2). Most students considered OMP to be an effective learning strategy (3.7). Students also stated that OMP teaching is less threatening (3.9). Other items in questionnaire were also rated between 3 to 5.None students rated any item with lesser mean scores.

Table 8: Perception of students (OMP group) on 5 point likert's scale (Strongly agree=5, Agree=4, Neutral=3, Disagree $=2$, Strongly disagree $=1$ )

\begin{tabular}{|c|l|c|}
\hline & \multicolumn{1}{|c|}{ Questions } & $\begin{array}{c}\text { Mean } \\
\text { perception } \\
(\mathbf{n = 3 0})\end{array}$ \\
\hline 1. & You are comfortable with OMP & 4 \\
\hline 2. & OMP enhances the reasoning ability & 4.3 \\
\hline 3. & OMP augments confidence in expressing oneself. & 4.0 \\
\hline 4. & OMP leads optimum utilization of time. & 4.1 \\
\hline 5. & $\begin{array}{l}\text { In your opinion the participating faculty was comfortable } \\
\text { with the OMP }\end{array}$ & 4.2 \\
\hline 6. & $\begin{array}{l}\text { Overall environment generated by OMP is conducive for } \\
\text { learning }\end{array}$ & 4.0 \\
\hline 7. & $\begin{array}{l}\text { From teaching perspective OMP is good tool for rapport } \\
\text { building with teachers beyond teaching }\end{array}$ & 4.3 \\
\hline 8. & $\begin{array}{l}\text { OMP outscores other teaching methods in building concepts } \\
\text { of the subject }\end{array}$ & 4.2 \\
\hline 9. & OMP brings out strengths and weaknesses in you & 4.6 \\
\hline 10. & OMP generates non-threatening atmosphere & 3.9 \\
\hline 11. & $\begin{array}{l}\text { OMP helps in updating you regarding recent trends and } \\
\text { stimulates you for further reading }\end{array}$ & 4 \\
\hline 12. & Feedback was provided every time & 4.1 \\
\hline 13. & Feedback was helpful & 3.8 \\
\hline 14. & Your faculty covered all the microskills everytime & 4.4 \\
\hline 15. & $\begin{array}{l}\text { This method should be a regular part of undergraduate } \\
\text { teaching program. }\end{array}$ & 3.7 \\
\hline
\end{tabular}




\section{Discussion}

It is the need of hour that medical undergraduates should be competent to serve the society and for this more competency based, organized and structured teaching is required in Pharmacology as also observed in a previous study. ${ }^{10}$ Moreover students are not actively involved in traditional way of teaching. In this study OMP had been introduced to teach competencies in Pharmacology by framing clinical case scenarios to mimic the realistic clinical settings. OMP facilitate teachers to efficiently assess, teach and give feedback more proficiently. Previous studies have shown the effectiveness of OMP over the traditional teaching in clinical specialties ${ }^{3,11,12}$ However, its use in non/paraclinical subjects has been very limited. There are few examples in literature where OMP has been used as a teaching tool in subjects like Anatomy and Pathology ${ }^{13,1,8}$ In the present study we noted that both the teaching methods had significant impact on immediate cognitive gain. However, OMP was found to have greater impact on both immediate and long term gain than traditional for all the competencies. Our observations are in line with few studies conducted in the subject Pathology who found improved histopathological diagnostic skills after OMP intervention. ${ }^{1,8}$ Since no such similar studies have been conducted in this regard in the subject of Pharmacology, so we could not compare our findings.

The strength of OMP lies in the immediate feedback incorporated as one of the micro skill which helped learners to be aware of their mistakes, to reflect upon it and to improve upon further. This has also been corroborated by other studies. ${ }^{2}$ There is no formal, systematic and immediate feedback approach in traditional teaching and to give or not to give feedback solely depends on attitude of teacher This has also been mentioned in other studies. ${ }^{8,14}$

Our faculties rated overall OMP process on the scale more than 3. Mostly all participants agreed that OMP raised overall performance of students, brought out strengths and weaknesses of students, covered all microskills including feedback everytime. They also agreed that OMP creates healthy relationship between preceptor and learner. Because of this students could freely communicate with the faculties. They also agreed that OMP improves reasoning skills of the students. Similar type of results were mentioned in earlier conducted studies. ${ }^{11,12,15,16}$ Our faculties also agreed that time constraints were there with OMP as it was found to be time consuming. This finding was supported by the study of Gulati H K. ${ }^{1}$ As mentioned in one study that time should not be the strict criterion for conducting OMP but it is the process which is more important. ${ }^{17}$ Also as stated by John O. Nehar (1992) that the OMP model is most helpful when it is not viewed as static but as a pliable set of guidelines that can be shuffled. Our learners also welcomed OMP as a useful teaching learning methodology. Most of them agreed that OMP had promising effect than other teaching methods in building concepts of the subject. The learners also opined that feedback and discussion about general rules had a significant impact on their learning and reasoning skills. They further stated that this concept of one to one interaction with the preceptor individually gave them a better chance to clarify their doubts and preceptor were also keen to understand their learning needs. Our findings were corroborated with those of previous studies. ${ }^{11,3,18,19}$ Learners further stated that teaching skills of faculty had also improved. Neher et al also reported OMP to be brief, easy to understand which also improves teaching skills. ${ }^{20}$ Furney et al in randomized controlled trial reported OMP to improve teaching skills. ${ }^{4}$

In this regard study by Chen LK et al did not support our observations which revealed that use of OMP by trained experienced anatomy teachers did not have positive impact on the student learning perception in the gross anatomy laboratory. ${ }^{13}$ Fixed steps in OMP might hinder their teaching performance probably because of the fact that the experienced teachers had already developed their own teaching approaches. ${ }^{21}$ However the novice teachers were interested in OMP. They considered the OMP to be very useful for their development as anatomy teachers. ${ }^{22}$

\section{Conclusion}

There is potential of using the OMP in achieving the core competencies in the subject of Pharmacology. The main strength of the study lies in the systematic approach in teaching and immediate feedback which is incorporated in the 5 microskills covered in OMP.

The topic should be from the 'must know' area of the pharmacology syllabus and should have already been taught by traditional didactic lectures. The model has been well received by both faculty members and students.

\section{References}

1. Gulati H K. One minute preceptor - introduction and perception evaluation of a novel teaching tool for teaching routine histopathology slides to postgraduate students in pathology. Indian Journal of Pathology and Oncology, July-September 2016;3(3);503-7.

2. Weitzel KW, Walters EA, Taylor J. Teaching clinical problem solving: a preceptor's guide. Am J Heath Syst Pharm. 2012;6:1588-99.

3. Aagaard E, Teherani A, Irby D M. Effectiveness of the One-Minute Preceptor Model for Diagnosing the Patient and the Learner: Proof of Concept. Acad Med. 2004;79:42-9.

4. Furney SL, Orsinin AN, Orsetti KE, Stern DT, Gruppen LD, Irby DM. Teaching the one-minute preceptor: a randomized controlled trial. J Gen Intern Med 2001;16:620-4.

5. Neher JO, Gordon KC, Meyer B, Stevens N. A five-step "Microskills" Model of clinical teaching. JABFP 1992;5:419-24. 
6. Singh T, Gupta P, Singh D. Test and item analysis in principles of medical education. Fourth ed. New Delhi Jaypee Brothers Medical Publishers (P) Ltd; 2013: p.10813.

7. Waikar M, Singh A. Introduction of OMP (One Minute Preceptor) As a Teaching Tool for Post Graduates in the Department of Obstetrics and Gynecology . JETHS 2 ;2015: 62-6.

8. Dawande P, Kale A, Vagha S. One Minute Preceptorship Programme for Teaching Postgraduate Students in Pathology. JHSE Vol 2, No. 1,1-6.

9. Zakrajsek T. The One Minute Preceptor Applied to A Variety of Situations. The scholarly teacher. Applying evidence based strategies to enrich student learning.

10. Ward F, Miolszweski K (2002) Evaluation of the impact of pharmacist-led therapeutic tutorials on third-year medical students' knowledge and understanding of drugs used in clinical practice. Med Teach 24: 628-33.

11. 11.Teherani A, O'Sullivan P, Aagaard EM, Morriso EH, Iry DM. Student perceptions of the one minute preceptor and traditional preceptor models. Med Teach 2007 May;29(4):323-7.

12. 12.Harkare Vivek H, Deosthale N, Dhoke P, Khadakkar S.Use of One Minute Preceptor( OMP) for effective clinical teaching in ENT for Final MBBS students, PJMS, 2013; 2(3):50-2.

13. 13. Chan L K, Wiseman J. Use of the one-minute preceptor as a teaching tool in the gross anatomy laboratory. Anat sci Educ 2011;4:235-8.

14. 14. Opitz B, Ferdinand N K, and Mecklinger A.Timing Matters: The Impact of Immediate and Delayed Feedback on Artificial Language Learning. Front Hum Neurosci. 2011;5:8

15. 15.Dandekar KN*, Jorwekar GJ, Baviskar PK, Apturkar DK, Shaikh MH, Koppad S.N Use of "One Minute Preceptor" in surgery OPD in Rural Medical College, IJBAR ,2013:04(01).

16. 16. Misar S, Desai P, Kuchewar V. Perception of Post Graduate Students of Ayurveda Towards One Minute Preceptor Model. JHSE. 2015 Vol 2, No.2.70-3.

17. 17. Bott G1, Mohide EA, Lawlor Y. A clinical teaching technique for nurse preceptors: the five minute: J Prof Nurs. 2011 Jan-Feb; 27(1):35-42.

18. 18. Eckstrom E, Homer L, Judith L. Bowen. Measuring Outcomes of a One-Minute Preceptor Faculty Development Workshop J Gen Intern Med,2006;21:41014.

19. 19. Irby DM, Aagaard E, Teherani A. Teaching points identified by preceptorsobserving one-minute preceptor and traditional preceptor encounters, Acad Med, 2004;79:50-5.

20. 20. Neher J O, Stevens N J. The One-minute Preceptor: Shaping the Teaching Conversation. Fam Med 2003;35:391-3.

21. 21. Chan LK1, Sharma N. Study on effect of training experienced teachers in the use of the one minute preceptor technique in the gross anatomy.Anat Sci Educ. 2014 Mar-Apr;7(2):124-9.

22. 22. Chan LK, Yang J, Irby DM .Application of the oneminute preceptor technique by novice teachers in the gross anatomy laboratory. Anat Sci Educ. 2015 NovDec;8(6):539-46. 